\title{
Theoretical Analysis of Maximum Pulling Rate in Capillary Shaping of Pure Aluminum*1
}

\author{
Jun Yaokawa ${ }^{1, * 2}$, Yasushi Iwata ${ }^{1}$, Yoshio Sugiyama ${ }^{1}$, Mitsuhiro Kobayashi ${ }^{2}$ and Yuta Egawa ${ }^{2}$ \\ ${ }^{1}$ Toyota Central R\&D Labs. Inc., Nagakute 480-1192, Japan \\ ${ }^{2}$ Toyota Motor Corporation, Toyota 471-8571, Japan
}

\begin{abstract}
The capillary shaping is one of the most attractive options for the fabrication of aluminum frame components of a light weight car body structure. In this study, the maximum pulling rate of a pure aluminum fabricated by this technique was investigated using heat transfer analysis. Numerical and theoretical methods were applied to consider various cooling conditions. The maximum pulling rate depends on $h / b$, where $b$ is the thickness of a product and $h$ is the heat transfer coefficient between the coolant air and product. The maximum pulling rate increases with increasing $h / b$ and decreasing melt temperature. Critical cooling length, which contributes to increased pulling rate, is smaller than 100 mm and decreases with increasing $h / b$. [doi:10.2320/matertrans.F-M2018850]
\end{abstract}

(Received October 9, 2018; Accepted November 1, 2018; Published December 14, 2018)

Keywords: capillary shaping, pulling rate, critical cooling length, aluminum, heat transfer analysis

\section{Introduction}

Current demands for lightweighting of automobiles have led to the use of aluminum alloys for car body components. Capillary shaping is a promising technique for fabricating aluminum alloy components directly from an aluminum melt by pulling the melt upward and letting it solidify in air. This technique enables the forming of both casting and wrought alloys, for example, 6000 series alloys, despite their high hotcrack sensitivity. Directional solidification in this process prevents formation of solidification shrinkage porosity, permitting high strength and fracture strain. Thus, capillary shaping is an attractive option for fabricating aluminum alloy frames and other body structure components. ${ }^{1-9)}$

Previously, we investigated thermal stability during the pulling process, which affects the thickness accuracy of products. ${ }^{10)}$ However, there is a lack of understanding of the theoretical maximum pulling rate, although it is required to increase the pulling rate to achieve higher productivity in practical situations. Thus, arbitrary pulling rate goals are set during development of the capillary shaping technique. In this study, therefore, we used heat transfer analysis to investigate the maximum pulling rate for shaping pure aluminum under the optimal conditions for cooling the product using blowing air.

\section{Method}

\subsection{Model for heat transfer analysis}

Figure 1 is a schematic illustration of the capillary shaping technique. ${ }^{10)}$ In this process, a shaping device that defines the cross-section of a product is placed on a melt surface. Then, the melt is withdrawn through openings in the shaping device using a starting device to form a melt column above the melt surface. The upper end of the melt column is a solid/liquid $(\mathrm{S} / \mathrm{L})$ interface. The product is formed with directional

\footnotetext{
${ }^{* 1}$ This Paper was Originally Published in Japanese in J. JFS 89 (2017) 631637.

${ }^{* 2}$ Corresponding author, E-mail: e1454@mosk.tytlabs.co.jp
}

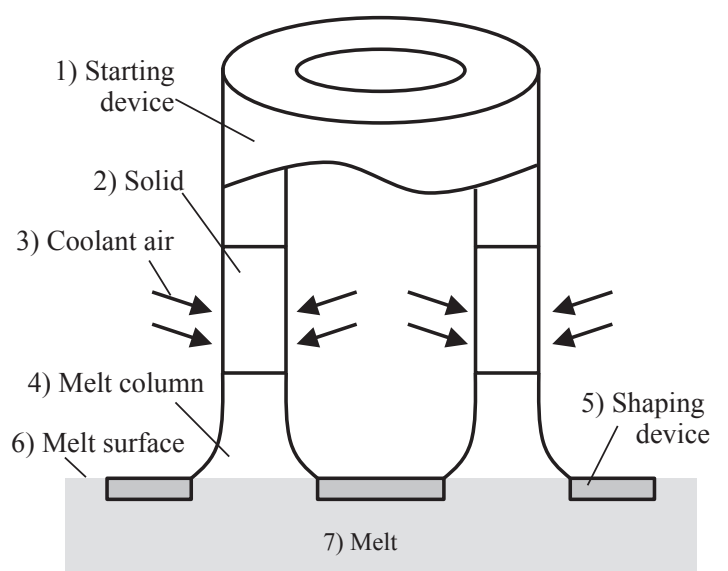

Fig. 1 Schematic illustration of capillary shaping of hollow product. ${ }^{10)}$

solidification by pulling the starting device upward while cooling the starting device or solidified portion above the $\mathrm{S} / \mathrm{L}$ interface. Since the solidification rate depends on the heat balance at the $\mathrm{S} / \mathrm{L}$ interface, the maximum pulling rate can be determined by a heat transfer analysis.

Figure 2 shows a model for analyzing the heat balance. ${ }^{7)}$ Figure 2(a) illustrates a cross section from the melt to the product. In the analysis, we assumed the following:

1) The opening width of the shaping device $B$ and product thickness $b$ are the same.

2) The solid surface is cooled within a range $L$ from the $\mathrm{S} / \mathrm{L}$ interface.

3) Coolant air temperature $T_{\infty}$ is constant and low enough for pulling.

4) Heat transfer coefficient $h$ between the coolant air and the solid is constant and high enough for pulling.

5) The melt and product move toward the pulling direction at constant pulling rate $u$.

Assumption 1) provides the thermally stable condition needed to obtain a product with uniform thickness. ${ }^{7,10)}$ The purpose of assumptions 6) through 9) was to simplify the calculations.

6) Temperature in the depth direction is the same. 
(a)

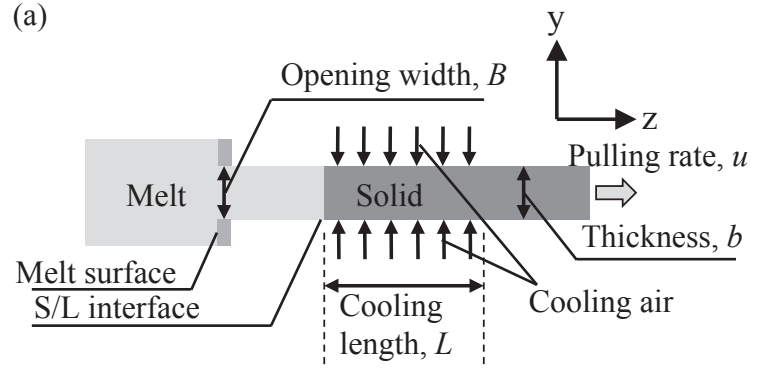

(b) Temperature gradient in the melt $\left|G_{L}\right|$

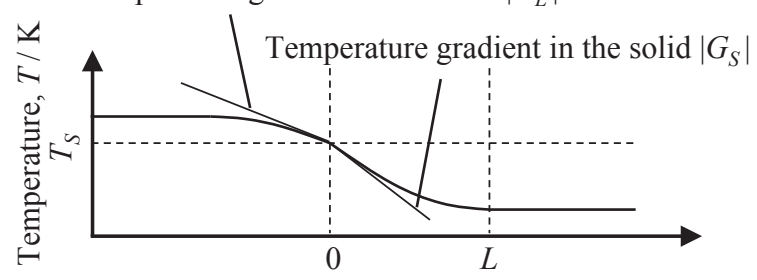

Distance from the solid-liquid interface, $z / \mathrm{mm}$

Fig. 2 Model for theoretical analysis of heat balance at the solid-liquid interface. $^{7)}$

7) Temperature difference in the width direction ( $y$-axis) is negligible.

8) Temperature distribution is in the steady state.

9) Material constants for the melt and solid have negligible temperature dependence.

From assumptions 6) and 7), the temperature distribution becomes one-dimensional, as shown in Fig. 2(b). The heat balance at the $\mathrm{S} / \mathrm{L}$ interface is given by eq. (1),

$$
Q_{1}=Q_{2}+Q_{3} \quad\left[\mathrm{~J} / \mathrm{m}^{2} \cdot \mathrm{s}\right]
$$

where $Q_{1}=\lambda_{S}\left|G_{S}\right|$ is the heat flux arising from the cooling of the solid, $Q_{2}=u\left(1-f_{s}\right) \rho \Delta H_{f}$ is the release rate of latent heat of solidification per unit time and unit area, and $Q_{3}=\lambda_{L}\left|G_{L}\right|$ is the heat flux conducting from the melt. Further, $\lambda$ is the thermal conductivity $[\mathrm{W} / \mathrm{m} \cdot \mathrm{K}], u$ is the pulling rate $[\mathrm{m} / \mathrm{s}]$, $\Delta H_{f}$ is the latent heat of solidification $[\mathrm{J} / \mathrm{kg}], \rho$ is the density $\left[\mathrm{kg} / \mathrm{m}^{3}\right], f_{s}$ is the solid fraction of the melt, and $G$ is the temperature gradient at the $\mathrm{S} / \mathrm{L}$ interface $[\mathrm{K} / \mathrm{m}]$. Subscripts $\mathrm{S}$ and $\mathrm{L}$ represent the solid and liquid phases, respectively. Since the temperature gradient is negative, absolute values are used in the equation. From eq. (1), $u$ is given by

$$
u=\frac{\lambda_{S}\left|G_{S}\right|-\lambda_{L}\left|G_{L}\right|}{\left(1-f_{S}\right) \rho \Delta H_{f}}
$$

The maximum pulling rate can be calculated by eqs. (1) or (2) as functions of $\left|G_{L}\right|, f_{S}$, and $\left|G_{S}\right|$. In this study, the maximum pulling rates of pure aluminum were calculated using the material constants listed in Table 1. The determination of variables $\left|G_{L}\right|, f_{s}$, and $\left|G_{S}\right|$ are described in the following sections.

\subsection{Temperature gradient of liquid and solid fraction}

As in the previous experimental results, ${ }^{7)}$ the temperature gradient of the liquid side $\left|G_{L}\right|$ was between 0 and $10 \mathrm{~K} / \mathrm{mm}$. In addition, the solid fraction was zero in most situations. However, a higher solid fraction is preferred to make the pulling rate higher, since it reduces the cooling required to
Table 1 Material properties of pure aluminum.

\begin{tabular}{ccc}
\hline Latent heat of solidification, $\Delta H_{f}$ & 395000 & $\mathrm{~J} / \mathrm{kg}$ \\
Density, $\rho^{11)}$ & 2595 & $\mathrm{~kg} / \mathrm{m}^{3}$ \\
Specific heat, $c$ & 1140 & $\mathrm{~J} / \mathrm{kg} \cdot \mathrm{K}$ \\
Thermal conductivity of solid, $\lambda_{S}{ }^{12,13)}$ & 210 & $\mathrm{~W} / \mathrm{m} \cdot \mathrm{K}$ \\
Thermal conductivity of liquid, $\lambda_{L}{ }^{12,13)}$ & 92 & $\mathrm{~W} / \mathrm{m} \cdot \mathrm{K}$ \\
Solidification Temperature, $T_{S}$ & 933 & $\mathrm{~K}$ \\
\hline
\end{tabular}

extract the latent heat of solidification. Therefore, we investigated the maximum pulling rate assuming four melt conditions: (1) $\left|G_{L}\right|=10 \mathrm{~K} / \mathrm{mm}, f_{s}=0$; (2) $\left|G_{L}\right|=0 \mathrm{~K} / \mathrm{mm}$, $f_{s}=0$; (3) $\left|G_{L}\right|=0 \mathrm{~K} / \mathrm{mm}, f_{s}=0.1$; and (4) $\left|G_{L}\right|=0 \mathrm{~K} / \mathrm{mm}$, $f_{s}=0.2$.

\subsection{Temperature gradient of the solid side}

Heat transfer analysis was carried out to determine the temperature gradient of the solid side $\left|G_{S}\right|$ of the S/L interface. The calculation area was the solid part shown in Fig. 2. Axes $z$ and $y$ were the pulling and thickness directions, respectively, and $z=0$ at the $\mathrm{S} / \mathrm{L}$ interface and $y=0$ at the center of the solid. The range of the thickness $b$ was $1 \leq b \leq 5 \mathrm{~mm}$. The solid moved along the $z$-axis at the pulling rate $u<5 \mathrm{~mm} / \mathrm{s}$ or remained stationary $(u=$ $0 \mathrm{~mm} / \mathrm{s})$. The temperature of the solid at the $\mathrm{S} / \mathrm{L}$ interface $(z=0)$ coincided with the melting point of pure aluminum $T_{s}$ [K] (i.e., no undercooling). The cooling length from the $\mathrm{S} / \mathrm{L}$ interface was $L[\mathrm{~mm}]$. The coolant air temperature was $T_{\infty}=323 \mathrm{~K}$, which satisfied the assumption of a temperature low enough for pulling. The heat transfer coefficients between a plate and air blown vertically onto it at $20 \mathrm{~m} / \mathrm{s}$ was experimentally measured to be $460 \mathrm{~W} / \mathrm{m}^{2} \cdot \mathrm{K}$. $\left.{ }^{14}\right)$ Therefore, the heat transfer coefficient between the coolant air and the solid surface $h$ was varied in the range $60 \leq$ $h \leq 500 \mathrm{~W} / \mathrm{m}^{2} \cdot \mathrm{K}$ to approximate a somewhat rigorous cooling condition. Insulated conditions were applied between the coolant air and the solid at locations other than the cooling length $(z>L)$. Under these conditions, both the theoretical and numerical methods were used to determine the temperature gradient of the solid side $\left|G_{S}\right|$.

\subsubsection{Theoretical analysis}

At the pulling rate $u=0 \mathrm{~mm} / \mathrm{s}$ and a negligible temperature difference in the width direction ( $y$-axis), the distribution of temperature $T$ in the solid along the $z$-axis is given by an analytical solution of a rectangular fin. ${ }^{15}$ )

$$
T=T_{\infty}+\left(T_{S}-T_{\infty}\right) \frac{\cosh [M(L-z)]}{\cosh (M L)},
$$

where

$$
M=\sqrt{\frac{2 h}{b \lambda_{S}}} .
$$

The temperature gradient of the solid side $G_{S}$ is derived from a derivative of eq. (3) with respect to $z$ at $z=0 \mathrm{~mm}$ and is given by eq. (5),

$$
G_{S}=\left.\frac{d T}{d z}\right|_{z=0}=-M\left(T_{S}-T_{\infty}\right) \tanh (M L) .
$$

Since $G_{S}$ is negative, it is expressed as its absolute value $\left|G_{S}\right|$. If thickness $b$ and heat transfer coefficient $h$ are constant, the 
maximum temperature gradient of the solid side $\left|G_{S}\right|_{\max }$ is obtained at $L \rightarrow \infty$ as

$$
\left|G_{S}\right|_{\max }=\lim _{L \rightarrow \infty}\left|G_{S}\right|=M\left(T_{S}-T_{\infty}\right) .
$$

However, because the cooling length is actually finite, a viable temperature gradient $\left|G_{S}{ }^{*}\right|$ must be lower than $\left|G_{S}\right|_{\max }$, that is,

$$
\frac{\left|G_{S}^{*}\right|}{\left|G_{S}\right|_{\max }}=E<1
$$

where $E$ is a ratio of $\left|G_{S}{ }^{*}\right|$ and $\left|G_{S}\right|_{\max }$. This study assumed $\left|G_{S}{ }^{*}{ }_{0.95}\right|$, that is, that the temperature gradient of the solid side at $E=0.95$ was an achievable temperature gradient with a finite cooling length, and it was used for calculating the maximum pulling rate. $L^{*}$ represents the cooling length required to obtain $\left|G_{S}{ }^{*}\right|$, and $L^{*}{ }_{0.95}$ is defined as the cooling length at $E=0.95$.

$L^{*}{ }_{0.95}$ and $\left|G_{S}{ }^{*}{ }_{0.95}\right|$ are obtained as follows: as the cooling length approaches $L^{*}{ }_{0.95}$, the temperature gradient of the solid side increases to $95 \%$ of $\left|G_{S}\right|_{\max }$ obtained by the infinite cooling length. Thus, $L^{*}{ }_{0.95}$ represents the critical cooling length required for practical sufficient cooling. However, increasing the cooling length beyond $L^{*}{ }_{0.95}$ improves the temperature gradient of the solid side by at most $5 \%$ of $\left|G_{S}\right|_{\max }$, which contributes to a slight incremental increase in the maximum pulling rate.

$L^{*_{0.95}}$ and $\left|G_{S}{ }^{*}{ }_{0.95}\right|$ are derived as follows. From definitions of $\left|G_{S}{ }^{*}\right|$ and $L^{*}$ and eq. (5),

$$
\left|G_{S}^{*}\right|=M\left(T_{S}-T_{\infty}\right) \tanh \left(M L^{*}\right) .
$$

From eqs. (6), (7), and (8),

$$
\frac{\left|G_{S}^{*}\right|}{\left|G_{S}\right|_{\max }}=\tanh \left(M L^{*}\right)=E
$$

Thus,

$$
L^{*}=\frac{\tanh ^{-1}(E)}{M},
$$

and $L^{*}{ }_{0.95}$ is obtained by substituting $E=0.95$ for eq. (10). From eqs. (6) and (7),

$$
\left|G_{S}^{*}\right|=M\left(T_{S}-T_{\infty}\right) E .
$$

$\left|G_{S}{ }^{*}{ }_{0.95}\right|$ can be calculated by substituting $E=0.95$ for eq. (11). Eliminating $M$ from eqs. (10) and (11) gives

$$
\left|G_{S}^{*}\right|=\frac{\tanh ^{-1}(E)\left(T_{S}-T_{\infty}\right) E}{L^{*}} .
$$

This relationship between $L^{*}$ and $G_{S}^{*}$ is used to produce $L^{*}-G_{S}{ }^{*}$ curves. Equation (12) is used in a later discussion.

\subsubsection{Numerical analysis}

Numerical analysis was carried out to determine the temperature distribution in the solid under pulling rates $u \geq 0 \mathrm{~mm} / \mathrm{s}$, and then the temperature gradient of the solid side $\left|G_{S}\right|$ was obtained. Figure 3 shows the model for the numerical analysis. Because the temperature distribution in the thickness direction was symmetrical about the center-line, the numerical analysis was conducted using only half of the model, where the center-line boundary condition was insulated $(h=0)$, as shown in Fig. 3. The other boundary conditions were the same as those in the theoretical analysis,

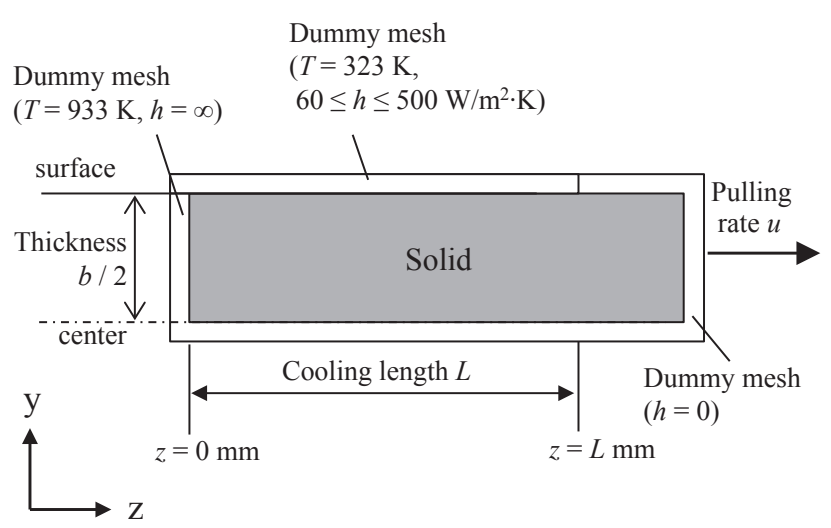

Fig. 3 Model for numerical calculation of temperature distribution in solid.

that is, constant temperature at the $\mathrm{S} / \mathrm{L}$ interface $\left(T=T_{S}=\right.$ $933 \mathrm{~K})$, constant coolant air temperature $\left(T_{\infty}=323 \mathrm{~K}\right)$, constant heat transfer coefficient between the coolant air and solid, and an insulated condition at other locations.

The heat transfer equation with unidirectional movement is given by

$$
\rho c\left(\frac{\partial T}{\partial t}+u \frac{\partial T}{\partial z}\right)=\frac{\partial}{\partial z} \lambda\left(\frac{\partial T}{\partial z}\right)+\frac{\partial}{\partial y} \lambda\left(\frac{\partial T}{\partial y}\right) .
$$

The conductive terms in this equation were implicitly implemented with the two-dimensional finite volume method $^{16-19)}$ using 0.1-mm-square meshes for the solid in Fig. 3. To account for advection heat transfer, the time interval to implement the conductive heat transfer was given by $\Delta t=\Delta z / u$ at $u>0 \mathrm{~mm} / \mathrm{s}$, and all variables in each mesh were moved to the next mesh in the $z$-direction after each conductive term calculation step. Dummy meshes were used for considering the advection heat transfer through the boundaries; that is, the variables of dummy meshes flowed into the solid meshes of the $\mathrm{S} / \mathrm{L}$ interface at $z=0 \mathrm{~mm}$, while the variables at the terminus of the solid flowed out to the dummy meshes. In contrast, the time interval at $u=0 \mathrm{~mm} / \mathrm{s}$ was given by the stability condition of the explicit implementation technique, since no advection terms were taken into account. The numerical analysis was continued until the temperature distribution became a steady state, and then the temperature gradient of the solid side $\left|G_{S}\right|$ was determined. This means that the calculation results were independent of the initial conditions. The criterion for judging whether the calculation approached the steady state was that the temperature of each mesh differed from that of the previous calculation time step by less than $0.0005 \mathrm{~K}$. This corresponds to about $1 \mathrm{ppm}$ of the temperature difference between the melting point of aluminum and the coolant air.

The temperature gradient of the solid side $\left|G_{S}\right|$ increased with increasing cooling length $L$ in both the numerical and theoretical methods. In the numerical analysis, however, the cooling length is finite. It is also important that the temperature gradient of the solid side $\left|G_{S}\right|$ varies slightly when $L \geq 100 \mathrm{~mm}$, as discussed below. Therefore, a viable temperature gradient for $\left|G_{S}{ }^{*}\right|$ in the numerical analysis was defined as

$$
\left|G_{S}{ }^{*}\right|=E\left|G_{S, L=200}\right|
$$




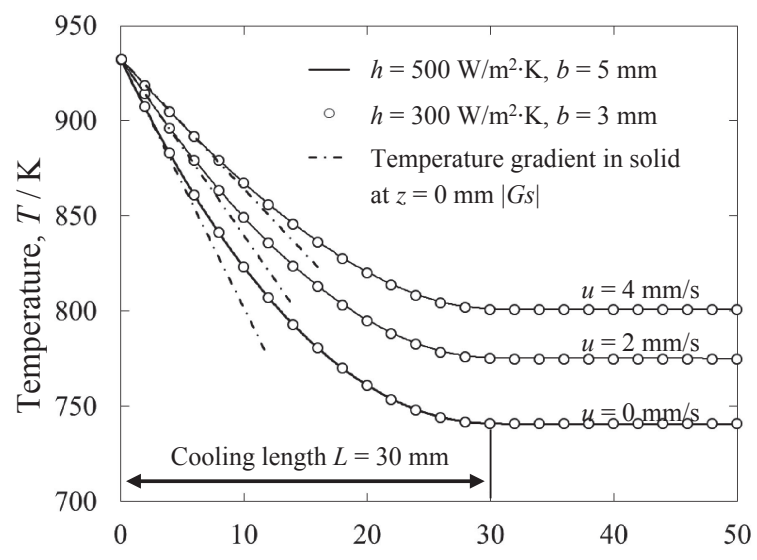

Distance from the solid-liquid interface, $z / \mathrm{mm}$

Fig. 4 Temperature distributions in solid calculated by numerical method.

where $\left|G_{S, L=200}\right|$ is the temperature gradient of the solid side calculated with an adequate cooling range $(L=200 \mathrm{~mm})$. In the theoretical method, $\left|G_{S}{ }^{*} 0.95\right|$ was determined by substituting $E=0.95$ for eq. (14) and the result was used for calculating the maximum pulling rate. In the numerical analysis, $L^{*}{ }_{0.95}$ also represented the critical cooling length at $E=0.95$. The calculation length in the $z$-axis for the numerical analysis does not affect the calculation results as long as it is larger than the cooling range. Thus, this study used a calculation length less than or equal to $200 \mathrm{~mm}$.

\section{Results and Discussion}

\subsection{Temperature gradient of the solid side}

Figure 4 shows the numerically calculated temperature distributions in the pulling direction at the center of the solid for heat transfer coefficient $h=500 \mathrm{~W} / \mathrm{m}^{2} \cdot \mathrm{K}$ and thickness $b=5 \mathrm{~mm}$, and $h=300 \mathrm{~W} / \mathrm{m}^{2} \cdot \mathrm{K}$ and $b=3 \mathrm{~mm}$, at the pulling rates $u=0,2$, and $4 \mathrm{~mm} / \mathrm{s}$ and cooling range $L=$ $30 \mathrm{~mm}$. The temperature distributions at $h=500 \mathrm{~W} / \mathrm{m}^{2} \cdot \mathrm{K}$ and $b=5 \mathrm{~mm}$ coincided with those at $h=300 \mathrm{~W} / \mathrm{m}^{2} \cdot \mathrm{K}$ and $b=3 \mathrm{~mm}$ for each pulling rate $u$. The temperature gradient of the solid side $\left|G_{S}\right|$, that is, the gradients at $z=0 \mathrm{~mm}$ in Fig. 4, decreased with increasing pulling rate $u$. The reason for these results is discussed below.

According to eqs. (3) and (4), the temperature distribution in the solid depends on the cooling length $L$ and $M=(2 h /$ $\left.b \lambda_{S}\right)^{1 / 2}$ when the pulling rate $u=0 \mathrm{~mm} / \mathrm{s}$ and the temperature difference in the thickness direction is negligible. Therefore, the same temperature distributions will be obtained under the conditions of constant $L$ and constant $h / b$. When $u>$ $0 \mathrm{~mm} / \mathrm{s}$, the same temperature distributions are also obtained at constant $L$ and $h / b$ values since the advection heat transfer is independent of $h / b$. In contrast, the advection heat transfer increases as the pulling rate $u$ increases, decreasing the temperature gradient of the solid side $\left|G_{S}\right|$.

It must be noted that a temperature difference appears in the thickness direction in the two-dimensional numerical analysis despite the assumption of no temperature difference in this direction in eq. (3). This indicates that the temperature difference between the center and surface of the solid increases at the same $h / b$ if both the heat transfer coefficient

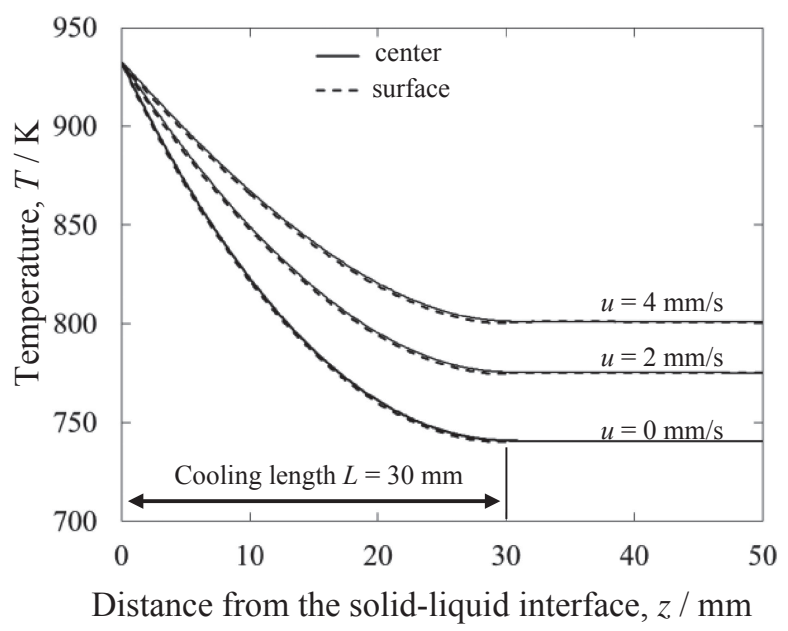

Fig. 5 Temperature distributions at surface and center of solid calculated by the numerical method at the heat transfer coefficient of $h=500$ $\mathrm{W} / \mathrm{m}^{2} \cdot \mathrm{K}$ and the solid thickness $b=5 \mathrm{~mm}$.

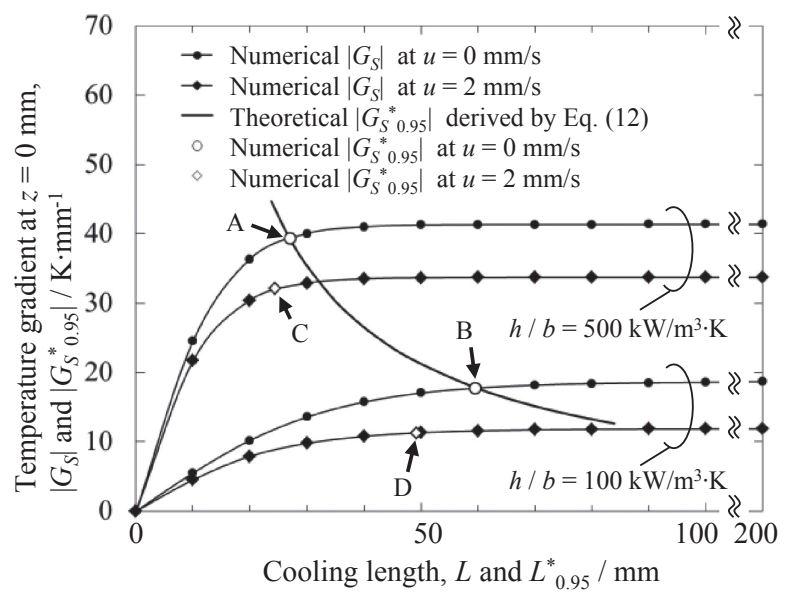

Fig. 6 Relationship between cooling length $L$ and temperature gradient in solid at solid-liquid interface $\left|G_{S}\right|$ calculated by numerical method, and relationship between cooling length $L^{*_{0.95}}$ and temperature gradient $\left|G_{S}{ }^{*}{ }_{0.95}\right|$ derived by eq. (12) and numerical method.

and thickness increase. Therefore, to confirm the validity of this assumption, Fig. 5 shows the temperature distributions in the center and at the surface of the solid calculated under the maximum heat transfer coefficient $h=500 \mathrm{~W} / \mathrm{m}^{2} \cdot \mathrm{K}$ and the maximum thickness $b=5 \mathrm{~mm}$ used in this study. Other conditions were the same as those used in Fig. 4, that is, the pulling rates were $u=0,2$, and $4 \mathrm{~mm} / \mathrm{s}$ and the cooling range was $L=30 \mathrm{~mm}$. Temperature differences between the center and the surface of the solid were quite small at each pulling rate. Therefore, the above assumption was valid under all conditions used in this study.

Figure 6 shows the temperature gradient of the solid side $\left|G_{S}\right|$ at $0 \leq L \leq 200 \mathrm{~mm}$ and $h / b=100$ and $500 \mathrm{~kW} / \mathrm{m}^{3} \cdot \mathrm{K}$, as calculated by the numerical method at $u=0 \mathrm{~mm} / \mathrm{s}$ (solid circles) and $u=2 \mathrm{~mm} / \mathrm{s}$ (solid diamonds). In Fig. 6 , the solid curve without symbols represents the analytical solution of the temperature gradients of the solid side at $E=0.95$, $\left|G_{S}{ }^{*}{ }_{0.95}\right|$, as determined by eq. (12). Open circles and open diamonds represent $\left|G_{S}{ }^{*} 0.95\right|$ determined by eq. (14) from the results of the numerical analysis at $u=0$ and $2 \mathrm{~mm} / \mathrm{s}$, respectively. The temperature gradient in the solid side $\left|G_{S}\right|$ 


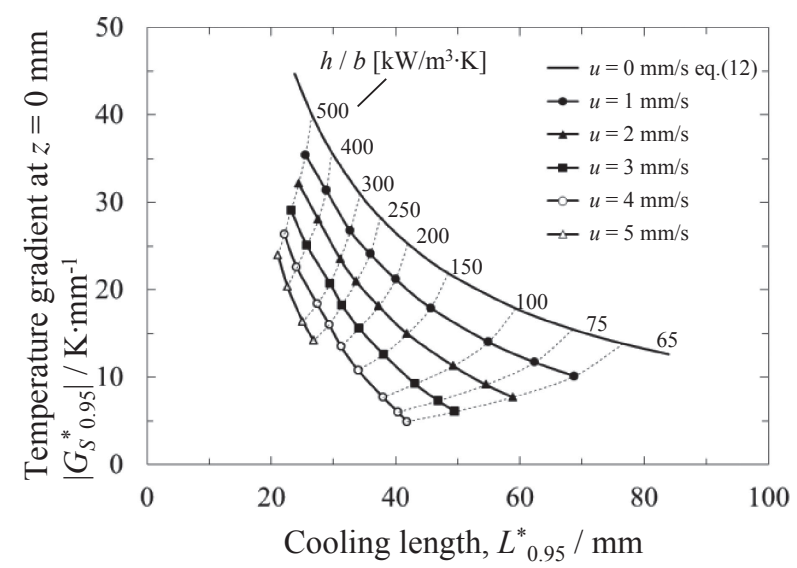

Fig. 7 Relationship between cooling length $L_{0.95}^{*_{0}}$ and temperature gradient in solid at solid-liquid interface $\left|G_{S}{ }^{*}{ }_{0.95}\right|$ calculated at various heat transfer coefficients to thickness ratios $h / b$ and pulling rates $u$.

(solid circles and solid diamonds) increased with increasing cooling length $L$ at each $u$ and $h / b$, and it approached its approximate maximum when $L \geq 100 \mathrm{~mm}$. In addition, $\left|G_{S}\right|$ increased with decreasing pulling rate $u$ and increasing $h / b$.

When the pulling rate $u=0 \mathrm{~mm} / \mathrm{s}$, numerically determined $\left|G_{S}^{*}{ }_{0.95}\right|$ (open circles) values are located on the $L^{*}-G_{S}{ }^{*}$ curve calculated by eq. (12), meaning that the numerical solutions agreed with the theoretical solutions. Thus, the validity of the numerical approach was confirmed. At $h / b=500 \mathrm{~kW} / \mathrm{m}^{3} \cdot \mathrm{K}, \quad\left|G_{S}{ }^{*}{ }_{0.95}\right|=39.4 \mathrm{~K} / \mathrm{mm} \quad$ and $L^{*}{ }_{0.95}=27.0 \mathrm{~mm}$, as plotted by the open circle "A." Under these conditions, the temperature gradient of the solid side $\left|G_{S}\right|$ reached $39.4 \mathrm{~K} / \mathrm{mm}$ by cooling the solid $27 \mathrm{~mm}$ from the solid-liquid interface, while $\left|G_{S}\right|$ increased at most by $41.4 \mathrm{~K} / \mathrm{mm}$ by cooling with an infinite length. At $h / b=$ $100 \mathrm{~kW} / \mathrm{m}^{3} \cdot \mathrm{K}$ (open circle denoted by "B"), $\left|G_{S}{ }^{*}{ }_{0.95}\right|=$ $17.7 \mathrm{~K} / \mathrm{mm}$ and $L^{*}{ }_{0.95}=59.5 \mathrm{~mm}$. In comparison with these values at $h / b=500 \mathrm{~kW} / \mathrm{m}^{3} \cdot \mathrm{K},\left|G_{S}{ }^{*}{ }_{0.95}\right|$ decreased and $L^{*}{ }_{0.95}$ increased with decreasing $h / b$. This indicates that one way to increase the temperature gradient of the solid side $\left|G_{S}{ }^{*}{ }_{0.95}\right|$ is to increase $h / b$ (stronger cooling), although cooling must be applied much closer to the $\mathrm{S} / \mathrm{L}$ interface because of the shortened critical cooling length $L{ }^{*}{ }_{0.95}$ under a strong cooling condition.

When the pulling rate $u=2 \mathrm{~mm} / \mathrm{s}$ and $h / b=500$ $\mathrm{kW} / \mathrm{m}^{3} \cdot \mathrm{K}$ (open diamond "C"), $\left|G_{S}{ }^{*}{ }_{0.95}\right|=32.2 \mathrm{~K} / \mathrm{mm}$ and $L^{*}{ }_{0.95}=24.4 \mathrm{~mm}$. These values were smaller than those at $u=0 \mathrm{~mm} / \mathrm{s}$ (open circle "A"). Generally, an increased pulling rate reduces both $\left|G_{S}{ }^{*}{ }_{0.95}\right|$ and $L^{*}{ }_{0.95}$. Thus, to increase the pulling rate, it is necessary to apply the cooling closer to the $\mathrm{S} / \mathrm{L}$ interface so as to increase the cooling efficiency. In addition, $\left|G_{S}{ }^{*}{ }_{0.95}\right|=11.3 \mathrm{~K} / \mathrm{mm}$ and $L^{*}{ }_{0.95}=$ $49.3 \mathrm{~mm}$ at the open diamond " $\mathrm{D}$ "; these values are smaller than those at $u=0 \mathrm{~mm} / \mathrm{s}$ (open circle "B").

Figure 7 illustrates $L^{*}{ }_{0.95}$ and $\left|G_{S}{ }^{*}{ }_{0.95}\right|$ for $0 \leq u \leq 5$ $\mathrm{mm} / \mathrm{s}$ and $60 \leq h / b \leq 500 \mathrm{~kW} / \mathrm{m}^{3} \cdot \mathrm{K}$. As discussed above, $\left|G_{S}{ }^{*}{ }_{0.95}\right|$ increased and $L^{*}{ }_{0.95}$ decreased with increasing $h / b$ or decreasing $u$.

\subsection{The maximum pulling rate}

Figure 8 shows relationships between the pulling rate $u$ and the heat flux from the solid $Q_{1}$, the release rate of latent

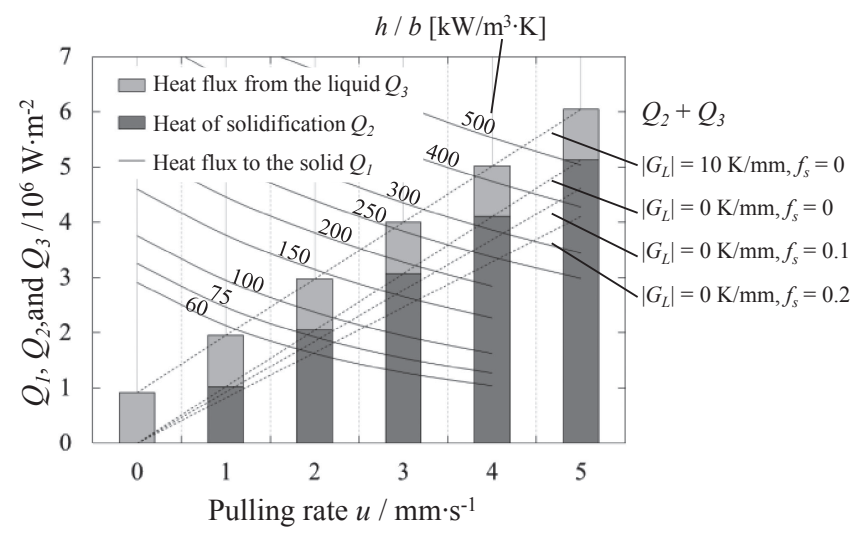

Fig. 8 Influence of pulling rate $u$ on heat flux to the solid $Q_{1}$, heat of solidification $Q_{2}$ and heat flux from liquid $Q_{3}$.

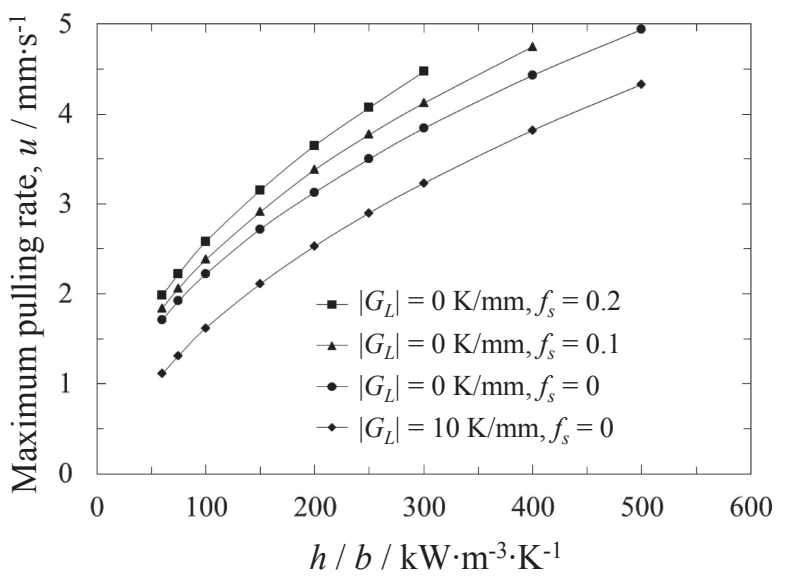

Fig. 9 Maximum pulling rate of the pure aluminum cooled by air at $323 \mathrm{~K}$ with various heat transfer coefficient to thickness ratios $h / b$ and the melt conditions derived by theoretical analysis.

heat of solidification $Q_{2}$, and the heat flux from the melt $Q_{3}$. In the figure, $Q_{1}$ was calculated as $Q_{1}=\lambda_{S}\left|G_{S}{ }^{*}{ }_{0.95}\right|$ using $\left|G_{S}{ }^{*}{ }_{0.95}\right|$ shown in Fig. 7 and represented by solid lines. Bar charts for $Q_{2}$ and $Q_{3}$ were determined by $Q_{2}=u\left(1-f_{s}\right) \rho \Delta H_{f}$ and $Q_{3}=\lambda_{L}\left|G_{L}\right|$ at the temperature gradient of the liquid side $\left|G_{L}\right|=10 \mathrm{~K} / \mathrm{mm}$ and the solid fraction $f_{s}=0$. Dashed lines represent the sums of $Q_{2}$ and $Q_{3}$ determined by four pairs of $\left|G_{L}\right|$ and $f_{s}$. Clearly, $Q_{1}$ decreased with increasing $u, Q_{2}$ was proportional to $u$, and $Q_{3}$ was independent of $u$. As the heat balance at the maximum pulling rate is given by $Q_{1}=$ $Q_{2}+Q_{3}$ in eq. (1), intersections of $Q_{1}$ (solid lines) and $Q_{2}+Q_{3}$ (dashed lines) indicate the maximum pulling rates.

Figure 9 shows the relationship between $h / b$ and the maximum pulling rates for pure aluminum cooled by air at $T_{\infty}=323 \mathrm{~K}$ under various $h$ and $b$. The maximum pulling rate increased when $h / b$ increased (which increased the cooling rate and reduced the wall thickness) and the temperature gradient of the liquid side $\left|G_{L}\right|$ was decreased or the solid fraction $f_{s}$ was increased (which lowered the melt temperature). The maximum pulling rate increased by about $0.5 \mathrm{~mm} / \mathrm{s}$ when the temperature gradient of the liquid side $\left|G_{L}\right|$ decreased and the fraction solid $f_{s}=0$. It additionally increased by about $0.5 \mathrm{~mm} / \mathrm{s}$ when the solid fraction was increased from 0 to 0.2 and temperature gradient of the liquid side was $\left|G_{L}\right|=0 \mathrm{~K} / \mathrm{mm}$. 


\subsection{Examples of the maximum pulling rates}

We can read the maximum pulling rates from Fig. 9 for shaping a product with wall thickness $b$, if we have the heat transfer coefficient for air cooling. A heat transfer coefficient of $h=460 \mathrm{~W} / \mathrm{m}^{2} \cdot \mathrm{K}$ was measured by blowing air perpendicular onto a plate at a flow velocity $w=20 \mathrm{~m} / \mathrm{s}^{14)}$ The mean heat transfer coefficient of the laminar flow heat transfer is given by ${ }^{20)}$

$$
\mathrm{Nu}=0.664 \operatorname{Re}^{1 / 2} \operatorname{Pr}^{1 / 3},
$$

where $\mathrm{Nu}=h x / \lambda_{\text {air }}$ is the Nusselt number, $\mathrm{Re}=x w / v$ is the Reynolds number, Pr is the Prandtl number, $\lambda_{\text {air }}$ is the thermal conductivity of air, $x$ is a characteristic length, and $v$ is the kinematic viscosity of the air. The material constants of the air at $320 \mathrm{~K}^{21)}$ are $\operatorname{Pr}=0.719, v=17.86 \times 10^{6} \mathrm{~m}^{2} / \mathrm{s}$, and $\lambda_{\text {air }}=27.59 \mathrm{~mW} / \mathrm{m} \cdot \mathrm{K}$. The characteristic length is $x=$ $50 \mathrm{~mm}$, which is close to the critical cooling length $L^{*}{ }_{0.95}$. Under these conditions, the heat transfer coefficients at the flow velocities $w=1,10$, and $20 \mathrm{~m} / \mathrm{s}$ are $h=17,54$, and $78 \mathrm{~W} / \mathrm{m}^{2} \cdot \mathrm{K}$, respectively. These values are much smaller than that obtained by measuring the effect of blowing air. In the capillary shaping apparatus, ${ }^{10}$ ) there were areas with direct and indirect air blowing, indicating that the actual heat transfer coefficient was spread between 17 and $460 \mathrm{~W} / \mathrm{m}^{2} \cdot \mathrm{K}$. By assuming $h=300 \mathrm{~W} / \mathrm{m}^{2} \cdot \mathrm{K}$ and $b=3 \mathrm{~mm}(h / b=$ $100 \mathrm{~kW} / \mathrm{m}^{3} \cdot \mathrm{K}$ ), the maximum pulling rate read from Fig. 9 is $2.2 \mathrm{~mm} / \mathrm{s}$ at $\left|G_{L}\right|=0 \mathrm{~K} / \mathrm{mm}$ and $f_{s}=0$.

\section{Summary}

A heat transfer analysis was carried out to determine the maximum pulling rate of pure aluminum in the capillary shaping technique. Our findings are as follows:

(1) The maximum pulling rate can be expressed as a function of $h / b$, where $h$ is the heat transfer coefficient between coolant air and a product and $b$ is the product wall thickness. The maximum pulling rate increases as $h / b$ increases, whereas the critical cooling length required to obtain sufficient cooling efficiency approaches the S/L interface with increasing $h / b$.

(2) The maximum pulling rate increased by about $0.5 \mathrm{~mm} / \mathrm{s}$ by decreasing the temperature gradient of the liquid side
$\left|G_{L}\right|$ from $10 \mathrm{~K} / \mathrm{mm}$ to $0 \mathrm{~K} / \mathrm{mm}$ at a constant solid fraction $\left(f_{s}=0\right)$.

(3) If capillary shaping from a semi-solid-state melt at $f_{s}$ values between 0.1 and 0.2 is possible, the maximum pulling rate would be about $1.0 \mathrm{~mm} / \mathrm{s}$ faster than that in shaping from a superheated melt at $\left|G_{L}\right|=10 \mathrm{~K} / \mathrm{mm}$ and $f_{s}=0$.

\section{REFERENCES}

1) A.V. Stepanov: Zh. Tech. Fiz. 29 (1959) 381-383.

2) A.V. Stepanov: Bull. Acad. Sci. U.S.S.R., Phys. Ser. 33 (1969) 17751782.

3) V.V. Peller and S.P. Nikanorov: Handbook of Aluminum, vol. 1, Physical Metallurgy and Processes, (CRC Press, 2003) p. 695.

4) A. Sato, Y. Ohsawa and G. Aragane: Mater. Trans. JIM 30 (1989) 5566.

5) A. Sato, Y. Ohsawa and G. Aragane: Mater. Trans. JIM 32 (1991) 7783.

6) A. Sato, Y. Ohsawa and G. Aragane: Mater. Trans. JIM 33 (1992) 6672.

7) J. Yaokawa, Y. Iwata, Y. Sugiyama, N. Sugiura and Y. Furukawa: Acta Mater. 104 (2016) 180-189.

8) J. Yaokawa, Y. Sugiyama, Y. Iwata, N. Sugiura and Y. Furukawa: Proceedings of the 72nd World Foundry Congress, (World Foundry Organization, 2016) O-29.

9) N. Sugiura, M. Kobayashi, Y. Furukawa, J. Yaokawa and Y. Iwata: Proceedings of the 72nd World Foundry Congress, (World Foundry Organization, 2016) O-30.

10) J. Yaokawa, Y. Iwata, Y. Sugiyama, M. Kobayashi and Y. Egawa: J. JFS 89 (2017) 396-401; Mater. Trans. 59 (2018) 963-968.

11) T. Magnusson and L. Arnberg: Metall. Mater. Trans. A 32 (2001) 2605-2613.

12) R. Brandt and G. Neuer: Int. J. Thermophys. 28 (2007) 1429-1446.

13) K.R. Horn: Aluminum, Vol. 1, Properties, Physical Metallurgy and Phase Diagrams (ASM) p. 1967.

14) F. Tachibana: Seisan Kenkyu 3 (1951) 399-400.

15) M. Shoji: Dennetsu Kougaku, (University of Tokyo Press, 1995) p. 75.

16) I. Ohnaka: Computer Dennetsu Gyouko Kaiseki Nyuumon, (Maruzen, 1985) p. 44.

17) K. Anzai: IMONO 64 (1992) 410-416.

18) J. Yaokawa and K. Anzai: J. JFS 75 (2003) 403-408.

19) A. Hasuno, K. Anzai and E. Niyama: Trans. Jpn. Soc. Mech. Eng., Ser. B 61 (1995) 1470-1476.

20) Dennetsu Kougaku Siryou, 4th edition, (The Japan Society of Mechanical Engineers, 1986) p. 45.

21) Dennetsu Kougaku Siryou, 4th edition, (The Japan Society of Mechanical Engineers, 1986) p. 329. 